\title{
ADAPTIVE STRUCTURES AND DESIGN CONCEPT OF TRANSFORMABLE JOINTS
}

\author{
Q. WANG \& P. TEUFFEL \\ Department of the Built Environment, Chair of Innovative Structural Design (ISD), \\ Eindhoven University of Technology, the Netherlands.
}

\begin{abstract}
This article describes the research framework for adaptive structures and the design concept of transformable joints. The research of adaptive structures can be splitted into different scales: deformation mechanisms (whole structure), cooperation mechanisms (inter-component) and actuation mechanisms (intra-component). This research will focus on transformable joints, which are based on special material properties (actuation) to accomplish the change of joint stiffness between locked and released states (transformation). Thereby, the control of DOF can be achieved, in order to finally realise the whole structure's form change (deformation). Alternatively under shock loads, the joints release and the structure occur certain deformation to dissipate energy and adjust to external loads. Afterwards, the structure recovers its original shape and removes residual strain through special/smart materials. Then the released joints relock again. By comparison of natural role models and adaptive structures, there are many similarities between them that we can learn from nature. In future research, e.g. adaptive stiffness, the experimental tests of potential materials and prototypes will be the main research methods. While for adaptive geometry, the knowledge of robotics, especially the part of geometric representations and transformations, will help to express this problem in mathematical way. This part will be mostly in conceptual level, so computer simulation will be used. The final goal of this research is to develop energy dissipation and shape-morphing strategies using transformable joints under varying loads as well as shock impact. These kinds of joints can not only be applied to tessellated shell structures, but also introduced to active facade systems.
\end{abstract}

Keywords: adaptive geometry, adaptive stiffness, control of DOF, deformation, energy dissipation, flexible components, stiff components, transformable joints.

\section{INTRODUCTION}

\subsection{Biomimetics research and technological transferring}

In nature, biological systems can change their physical/chemical properties to inhabit the environment for optimal survival [1]. Adaption processes in nature systems can be categorised into three levels: irritability (short time), growth (lifetime or phases of lifetime) and genetic evolution mechanism (several generations) [2].

Biomimetics means uses of mechanisms and functions of biological science in engineering, design, chemistry, electronics, and so on [3]. The biomimetic research processes are splitted into two main kinds: bottom up and top down. The former starts from a biotic product, then transfers such technologies to practical use by biomimetic research, whilst the latter begins with the technical problems, then searches for potential solutions from nature [4]. During the early stage of biomimetics, most cases were imitating the forms from natural 
creatures. Now biomimetic researches also focus on actuation mechanisms, behaviours, special properties of skin and biomaterials, which is from macro-structure scale to microstructure scale, even deep into nanostructure scale [5]. The principles of nature (heterogeneity, anisotropy hierarchy, multifunctionality and redundancy [6]), can also be transferred into building structures.

The keynotes of technological transferring are summarised as simulation, scaling and fabrication. Firstly, simulation gives us detailed anatomy to natural structure and material characteristics such as the mechanical and damping properties or heat and mass transport [7]. Specially, scaling is an important problem in biomimetic research. The common effects of scaling problems are dimension effect, load effect, size effect, height effect, dynamic effect and so on [8]. At the same time, with the combination of computer science and architecture, digital fabrication and construction technologies have been developed.

\subsection{Adaptive structures}

Natural creatures can optimally survive and adapt to external stimuli with instantaneous responses (consciously or unconsciously) or long-term evolutions (natural selection). Similarly, an adaptive structure is defined as "A structure whose geometric and inherent structural characteristics can be changed beneficially in response to external stimulation by either remote commands or automatic means [9]."

For adaptive structures, they are categorised into passive and active adaptabilities [10]. Currently, the applications of adaptive structures are summarised as four main parts: structural health monitoring, shape morphing, vibration (force and deformation) control and energy harvesting [11]. The realisation is closely related to the research of materials [12].

\section{STIFF COMPONENTS AND FLEXIBLE COMPONENTS INTEGRATED (SC\&FC) DESIGN METHOD}

The SC\&FC method describes the research framework to analyses adaptive structures from the angle of components. The research of adaptive structures can be splitted into different scales: deformation mechanisms (whole structure), cooperation mechanisms (intercomponent) and actuation mechanisms (intra-component).

\subsection{Natural concept generator}

It is observed that many structures consist of flexible components or stiff components or both of them. Taking a human arm or leg as an example, bones work as stiff components which support the whole frame, while muscles and soft tissues are flexible components which connect the bones and transfer the loads. When your arm curls up, the biceps contract and the triceps relax, with the deformation of shortening and extension, and vice versa. At the same time, the joints roll and slide due to the extension, torsion or compression of the ligaments in joints. During these movements, bones support the frame, bearing main loads but are barely deformed, or it may cause injury. If a human body is an adaptive structure, in which nerves are sensors and muscles are actuators, while the brain is the controller. However, to realise final smart or intelligent structures, the researches of the animals' nervous systems are still critical for the whole adaptive systems, which still is a long goal. For this research, the part of structure itself other than adaptive system is the keynote, so the following chapter goes back to the detailed introduction of flexible components and stiff components. 


\subsection{Stiff components (SC) and flexible components (FC) in structures}

Stiff components are defined as the main load-bearing components which support the internal and external loads (such as bones). They have large strength but little elastic deformation ability. When under stresses and forces, they can keep the initial shapes without deformation or with negligible deformation.

Flexible components are defined as the main deformation components which connect the stiff components and deliver loads (such as tendons and ligaments). For adaptive systems, flexible components can also play the role of actuators (muscles).

\subsection{Three mechanisms}

\subsubsection{Deformation mechanisms (scale of whole structure)}

The research of deformation mechanisms solves the main question-how the structure changes its geometry and configuration to adjust itself to external stimuli. In brief, this chapter introduces the shape-morphing approaches of the whole structure to realise adaptive geometry.

\subsubsection{Compliant mechanisms}

Compliant mechanisms widely exist in biology, especially in some plant movements. They can also be applied to small technical devices, but the applications in large building structure scale are still being explored [13]. For example, it is found in the bird-of paradise flower (Strelizia reginae, Strelitziaceae), a compliant mechanism triggered by external force, which means that one can artificially trigger the mechanism (elastic deformation) repeatedly. When a bird stands on the perch, a point-actuation causes bending in the rib, and this initial deformation then triggers a flapping motion of the wings. After the bird leaves (remove external force), the stored elastic energy in the deformed elements will reset the system afterwards $[14,15]$. There are the examples of rotatable hinge and lateral-torsional buckling, Fig. 1a [14].

\subsubsection{Pre-stress}

For these structures, when releasing the pre-stress, they deform a lot. Normally, such a movement is reversible, after reloaded, pre-stress recovers again. The underlying reason is that an object without stiffness can obtain stiffness when is pre-stressed and change the stiffness by

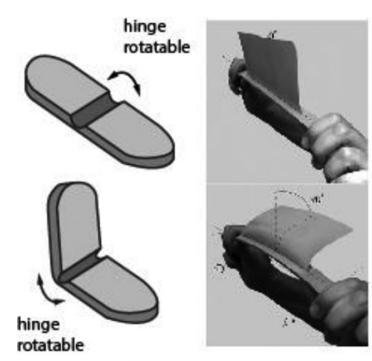

(a) compliant mechainism

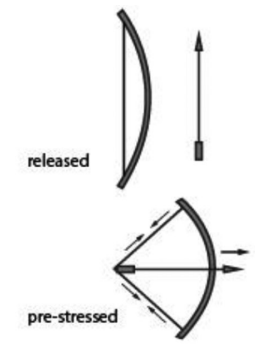

(b) pre-stress

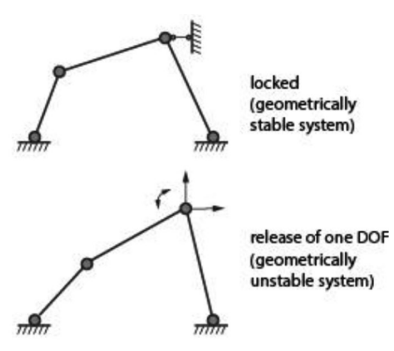

(c) control of DOF

Figure 1: Deformation mechanisms. (a) Compliant mechanism [14]; (b) Pre-stress; (c) Control of DOF. 
controlling the pre-stress. Typical examples as bow and spring also apply such deformation mechanism, Fig. $1 b$.

\subsubsection{Degree of freedom/constrain (DOF/DOC)}

Through special design of joints or linkages, which can be released or relocked, the DOF can be changed, thus we can control or restrain specific movements of the structures. Typical examples of these kind of structures are foldable structures (including origami-based folding structures), Fig. 1c.

\subsubsection{Cooperation mechanisms (scale of inter-component)}

The research of cooperation mechanisms solves the main question-how SC and FC work together. Generally, different relationships between SC and FC also mean that we should use different logics to design adaptive structures. From existing projects and cases, three main relationships can be summarised, namely, differentiation, fusion and transformation.

\subsubsection{Differentiation}

Stiff components bear loads (both compression and tension) without obvious deformation, while flexible components deform largely and transfer loads to stiff components, such as human joints. For this kind of structure, we use different materials in stiff components and flexible components, analysing each component and their cooperative performances on various load combinations. The designs of components and structures are controlled by ultimate bearing capacity (strength, stiffness and stability) and serviceability limit state (deflection and crack).

\subsubsection{Fusion}

For some plants, whose structures are multifunctional whole systems, it can still be regarded as consisting of stiff components (the parts that have little deformation during movements) and the flexible components (the parts that have large deformation and main actuation organs). The way to realise this kind of adaption is currently concerned with gradient materials. For instance, for the targeted control of porosity in concrete, they try to match the opposing properties of thermal conductivity (high porosity) and mechanical load bearing (low porosity) to meet local requirements. Besides, flexible materials such as FRP can also be used to realise configuration change and environmental adaption [6].

\subsubsection{Transformation}

The research of transformation mechanisms between stiff components and flexible components shows other kind of adaption, which triggers structural deformation because of the functional transformation between stiff components and flexible components, at the same time the load path and form change as well. In this kind of structure, the stiff components and flexible components can change from one to another, which is also the main concept of the design. One keynote for this transformable structure is controlling the distinct states of geometries and loads through special materials.

\subsubsection{Actuation mechanism (scale of intra-component)}

The research of actuation mechanisms solves the main question - the reason why the local stiffness can change to adapt to external environments, so this chapter focuses on adaptive stiffness. 


\subsubsection{Plant movements}

Actuation systems in plants can inspire bioinspired devices (active technical composites and moving devices), as these systems are actuated without mentalism. The movement mechanisms are based on cell growth, turgor pressure, cohesion forces and cell wall swelling or shrinking [16].

\subsubsection{Special material properties}

Materials which can react to environmental variation (temperature, humidity, loads and electricity, etc.) provide other kind of actuation. Smart materials are the main kind used widely in adaptive structures. Specifically, in this research, the potential materials should have the ability to realise reversible stiffness/phase change, between soft state and stiff state. Theoretically, the existing materials which can match the requirements are shape memory alloys/ polymers (SMAs/SMPs) [17, 18], phase change materials (PCMs), thermoplastic polymers [19], shear thickening fluids (STF) [20, 21] and magnetorheological fluids (MR fluids) [20].

\subsection{Design process}

The following is a preliminary flow chart which shows how the SC\&FC method works, that is, how to design an adaptive lightweight structure by starting with the thinking and concept of stiff components and flexible components. The flow graph will be developed along with the research, Fig. 2.

\section{TRANSFORMABLE JOINTS}

\subsection{Introduction}

Transformable joints are the kinds of joints which can adjust stiffness. As discussed before, they can be locked and unlocked. The reason why they are called 'transformable joints' is

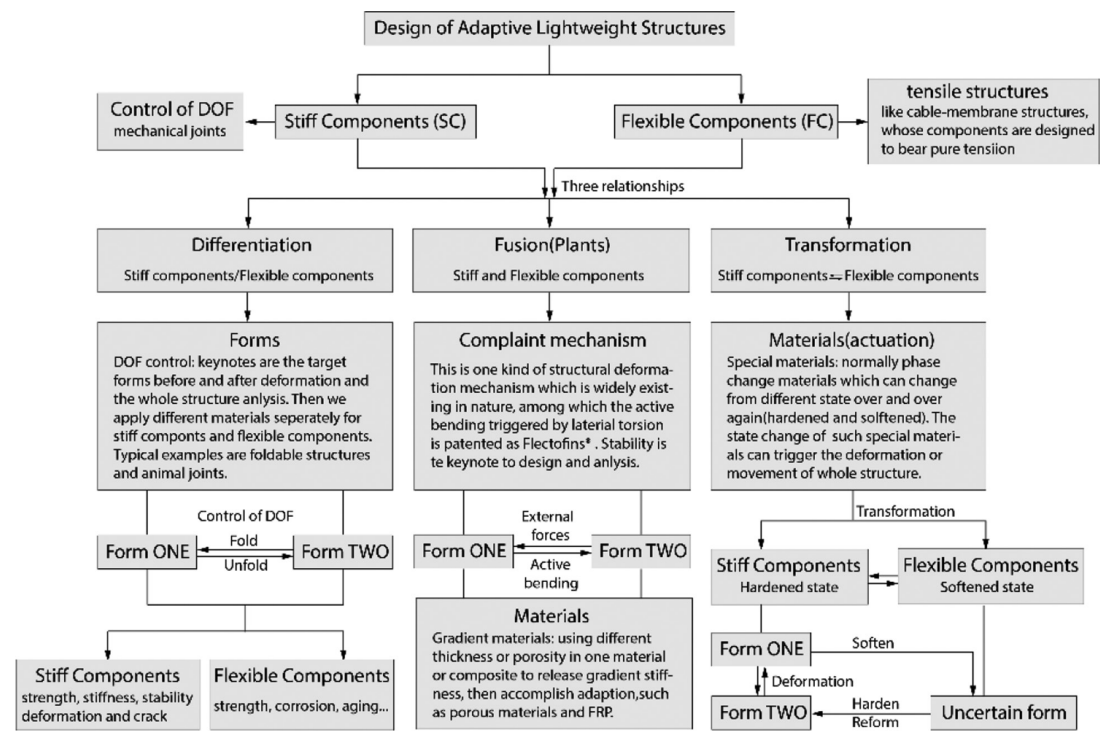

Figure 2: SC\&FC design flow chat. 
because transformable mechanisms will be introduced as the main method to accomplish adaptive stiffness.

For lightweight structures, structural adaption can be accomplished through adaptive stiffness and adaptive geometry [2]. The extreme situations of adaptive stiffness are stiff components and flexible components. Regarding the transformation (material state change or special damp devices) as actuation mechanism, actually, is the process of stiffness release or stiffness accumulation. In this research, not only the transformation processes will be discussed, also the extreme states (flexible and stiff, or totally unlocked and relocked). For the flexible extreme state, we focus on geometric adaption, which based on stiffness adaption. Hence, it is possible to combine adaptive stiffness with adaptive geometry.

In the SC\&FC flow chart, actually this research belongs to differentiation relationship combining with the transformation part (through different scale), Fig. 3. In large scale, the kind of cooperation mechanism is defined as differentiation, which is flexible joints connecting stiff elements (because the flexible joints can trigger deformation of whole structure), while focusing on flexible joints (in this situation: transformable joints), they can transform from stiff state (locked) to flexible state (unlocked) by adaptive stiffness. Here, the adaptive stiffness may depend on special materials properties or damping technologies.

In former research, from cases study, elements with variable length or variable stiffness shown dramatic contribution to active control of forces [2]. Hydraulically actuated 3-SPRparallel manipulator is applied in adaptive shell structure through the controlled positioning of the support points of structures [22]. There are few examples to manipulate the similar

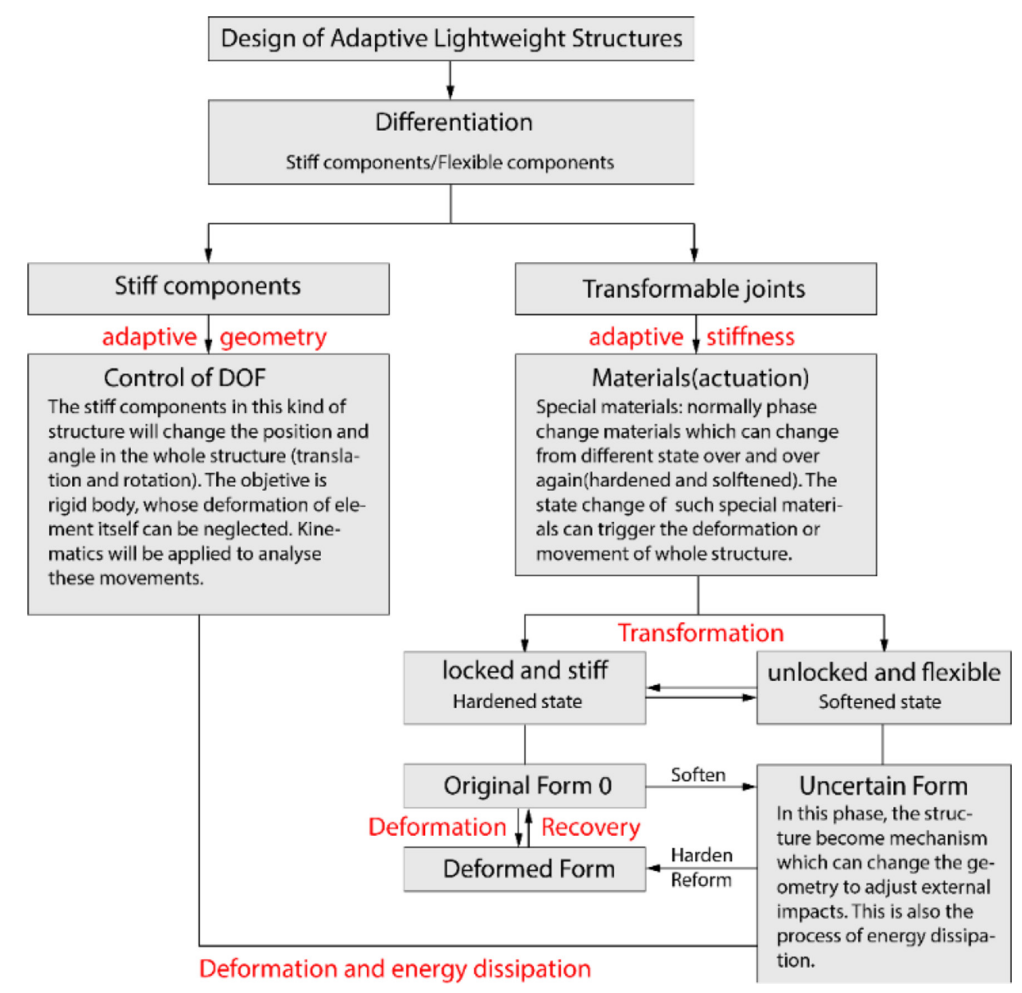

Figure 3: The research keynote in SC\&FC approach. 
technologies in joints, which are the effective and critical control point of adaptive structures, especially in tessellated shell structures. In the $\mathrm{PhD}$ project 'shock isolation using switchable stiffness' of University of Southampton, a novel stiffness control strategy applied to the problem of shock isolation is investigated. Firstly, two different models are considered for the theoretical analysis, then a different switchable stiffness strategy is identified. Finally, the practical implementation and experimental validation are presented in an experimental system, using experimental switchable stiffness devices [23, 24].

\subsection{Case studies}

\subsubsection{PCM joints}

One conceptual design of transformable joints uses PCM to accomplish the locked and released state of material and control the stiffness, Fig. 4. In this case, the material strength and geometric recovery are the current problems. To be more specific, the applications of PCMs in buildings are using their thermal performances, while even the solid state, the strengths are not strong enough. Furthermore, after deformation, the PCMs can change to solid state, but the whole structural geometry also changes. How to recover to the original state is still unsolved. If we can find the PCMs which have high strengths, or apply special constructional details (as in knee joints, the soft tissues and muscles are also without high strengths), PCM joints are also feasible. The states are controlled by temperature, which are especially suitable in active facade systems to response the change of temperature.

\subsubsection{SMA/SMP joints}

As for the concept of transformable joints, it is desired that if after deformation, the structure can recover to the original shape. Hence, SMAs or SMPs are quite promising materials to realise such requirements. This concept resembles to the application of SMPC hinge in space-deployable structures in aerospace [17], Fig. 5.

The transformable joints will be applied to tessellated structures or active facade systems, Fig. 6. Such structures consist of stiff units (SC) and transformable joints (FC). By controlling DOF (release or lock joints), the whole structural shape can be changed. While the

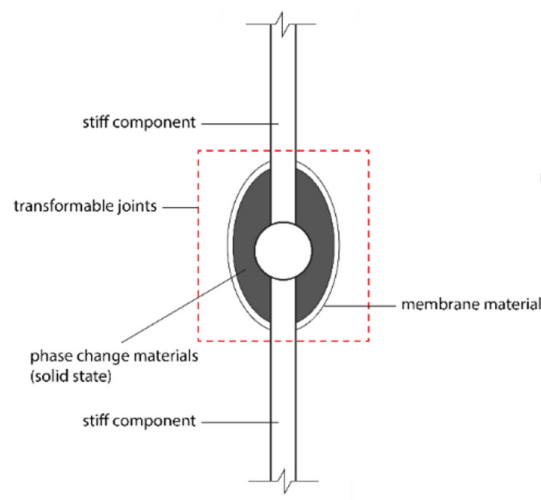

(a)

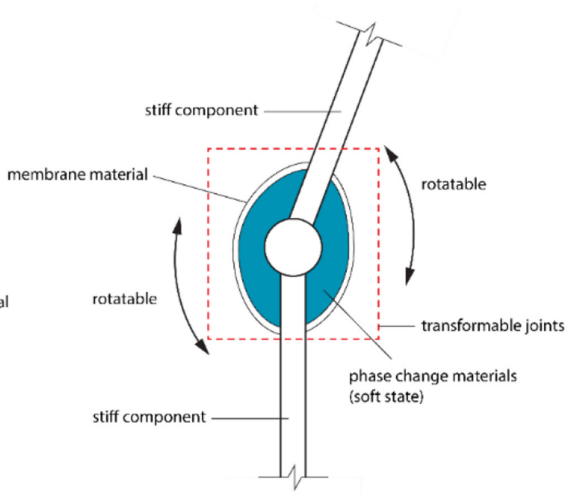

(b)

Figure 4: The concept of PCM joint. (a) Fixed joint with solid state PCM; (b) Flexible joint with soft state PCM. 


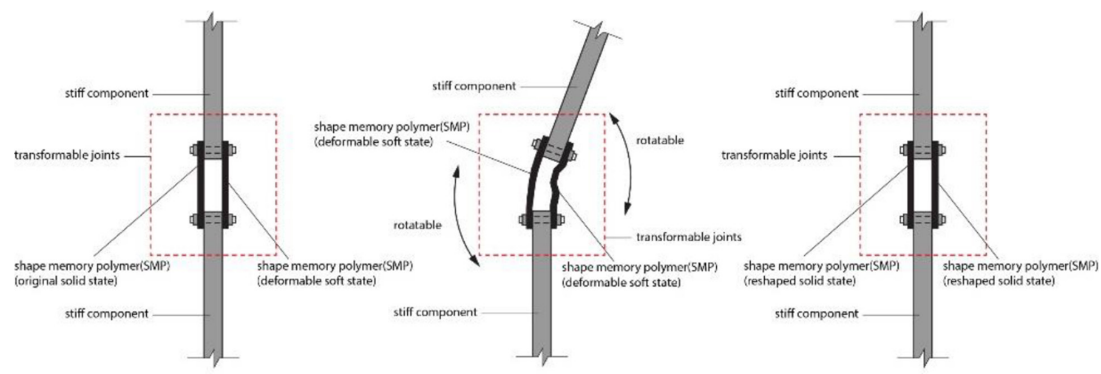

(a)

(b)

(c)

Figure 5: The concept of SMP joint. (a) Fixed joint with original solid state SMP; (b) Flexible joint with deformable soft state SMP. (c) Recover to original state.

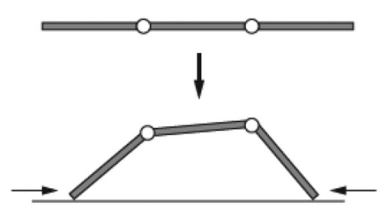

(a)Shape change

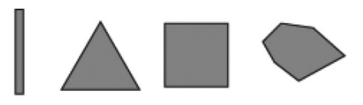

(b)stiff units of tessellated structures

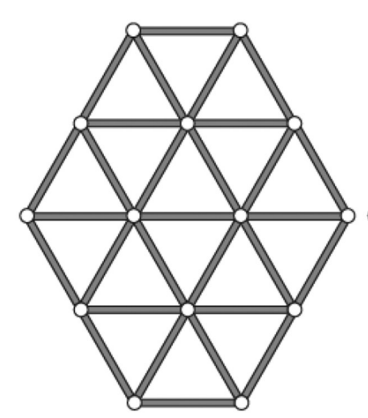

(c)rods+transformable joints

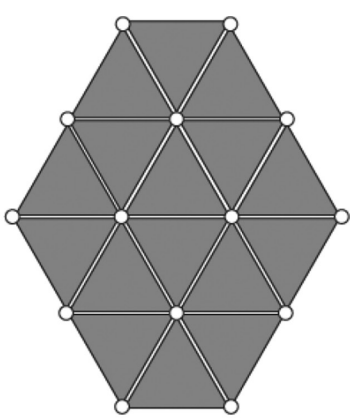

(d)plates+tansformable joints

Figure 6: Structural geometry. (a) shape change by DOF control; (b) stiff units connected by transformable joints (rot, triangle, rectangle or irregular polygon); (c) and (d) examples of tessellated structures.

stiff units can be rods or polygonal plates. The optimal units, constructional details of joins and shape-morphing strategies will be carried on in latter research.

\section{FUTURE RESEARCH}

As the concept generator of SC\&FC method, human joints in lower extremity are also valid references for transformable joints. The research of the relationships between bones, soft tissues and muscles contributes the exact definition and synergistic action of SC and FC. The principles of energy dissipation and energy absorption in soft tissues and muscles during landing or sport may be applied to develop energy dissipation strategy in such structures whose units connected by transformable joint.

Another interesting role model is echinoderms such as sea cucumber which can change the properties between the connective tissue and the hard parts of the skeleton, because of a composite with a thermoplastic matrix which could be softened and reshaped at ambient temperature [25]. The smart materials also can be the potential materials for the materialisation of transformable joints.

In Table 1, the main related researches of natural role models and adaptive structures include architecture, kinematics, kinetics and energy dissipation. For the division of labour of constituents, natural role models seem to be more complicated and of tight coordination, 
Table 1: Bio-inspiration: connections between natural role models and structures.

\begin{tabular}{|c|c|c|}
\hline & Natural role models & Adaptive structures \\
\hline $\begin{array}{l}\text { Architecture } \\
\text { (constituents) }\end{array}$ & $\begin{array}{l}\text { Knee (living biologic transmission); } \\
\text { ligament (sensate adaptive linkages); } \\
\text { articular cartilages (bearings); menisci } \\
\text { (mobile sensate bearings); muscles } \\
\text { (living engines) [26]; bones (SC). }\end{array}$ & $\begin{array}{l}\text { Load-bearing components (SC); } \\
\text { deformation components (FC); } \\
\text { transformable joints (similar } \\
\text { function as knee, FC). }\end{array}$ \\
\hline $\begin{array}{l}\text { Kinematics } \\
\text { (geometric } \\
\text { change) }\end{array}$ & $\begin{array}{l}\text { The trajectory of animal movements } \\
\text { (gait) }\end{array}$ & $\begin{array}{l}\text { The trajectory of stiff units and } \\
\text { joint movements (adaptive geom- } \\
\text { etry) }\end{array}$ \\
\hline $\begin{array}{l}\text { Kinetics } \\
\text { (actuation } \\
\text { mechanism) }\end{array}$ & $\begin{array}{l}\text { Muscles as drive engine (vertebrates); } \\
\text { stiffness change by smart materials } \\
\text { (sea cucumber); cell growth, turgor } \\
\text { pressure, cohesion forces and cell wall } \\
\text { swelling or shrinking (plant move- } \\
\text { ments) [19] }\end{array}$ & $\begin{array}{l}\text { Special material properties } \\
\text { (smart materials); other actuation } \\
\text { systems (motor) }\end{array}$ \\
\hline $\begin{array}{l}\text { Energy } \\
\text { dissipation }\end{array}$ & $\begin{array}{l}\text { Shape change of muscles; deformation } \\
\text { of soft tissues }\end{array}$ & $\begin{array}{l}\text { The stiffness change of trans- } \\
\text { formable joints and structural } \\
\text { oscillation; other damping } \\
\text { systems }\end{array}$ \\
\hline
\end{tabular}

while for kinematics, adaptive geometries will be more difficult as they have more DOF than gaits from animal movements. Indeed, they have some similarities of studies. Transformable joints are similar as knee joints which work as living biologic transmission (accept, transfer and dissipate) of loads [26].

\section{APPLICATIONS}

Based on the former research of active bending, vibration control, smart materials and joints design, the research of transformable joints provides another design strategy for structures which can also perform well under shock impact and natural disaster. Besides, they are suitable as inspirations for actuation devices or joint connections. The applications of such joints are not only in tessellated shells for smaller scale, they also provide promising solutions for active facade systems.

\section{REFERENCES}

[1] Miura, K. \& Furuya, H., Adaptive structure concept for future space applications. AIAA American Institute of Aeronautics and Astronautics Journal, 26(8), pp. 995-1002, 1988. http://dx.doi.org/10.2514/3.10002

[2] Sobek, W. \& Teuffel, P., Adaptive systems in architecture and structural engineering. SPIE's 8th Annual International Symposium on Smart Structures and Materials, pp. 36-45, 2001.

[3] Vincent, J.F., Bogatyreva, O.A., Bogatyrev, N.R., Bowyer, A. \& Pahl, A.K., Biomimetics: its practice and theory. Journal of the Royal Society Interface, 3(9), pp. 471-482, 2006.

http://dx.doi.org/10.1098/rsif.2006.0127 
[4] Magna, R., Gabler, M., Reichert, S., Schwinn, T., Waimer, F., Menges, A. \& Knippers, J., From nature to fabrication: biomimetic design principles for the production of complex spatial structures. International Journal of Space Structures, 28(1), pp. 27-40, 2013.

http://dx.doi.org/10.1260/0266-3511.28.1.27

[5] Wiedemann, M. \& Sinapius, M. (eds), Nano-micro-macro (Chapter 2). In Adaptive, Tolerant and Efficient Composite Structures, Springer Science+Business Media: New York, pp. 17-27, 2012.

[6] Knippers, J. \& Speck, T., Design and construction principles in nature and architecture. Bioinspiration \& Biomimetics, 7(1), pp. 15-25, 2012. http://dx.doi.org/10.1088/1748-3182/7/1/015002

[7] Multifunctional simulation of complex biological and biomimetic designs and materials; Germany IMFW/Universität Stuttgart, Biological Design and Integrative Structures, Krebs, A \& Buck, G. available at http://www.trr141.de/index.php/research-areas-2/b03/

[8] Lienhard, J. \& Knippers, J., Considerations on the scaling of bending-active structures. International Journal of Space Structures, 28(3), pp. 137-148, 2013.

[9] Adaptive structure. (n.d.) McGraw-Hill Dictionary of Scientific \& Technical Terms, 6E. available at http://encyclopedia2.thefreedictionary.com/adaptive+structure

[10] Habraken A.P.H.W., Sleddens W. \& Teuffel P.M., Adaptable lightweight structures to minimize material use. Proceeding of the 6th International Conference on Textile Composites and Inflatable Structures, Structures Membranes 2013, eds K.-U. Bletzinger, B. Kröplin \& E. Oñate.- S.1: Technische Universiteit Eindhoven, pp. 1-12, 2013.

[11] Gaudenzi, P., Introduction to smart structures (Chapter 1). Smart Structures: Physical Behaviour, Mathematical Modelling and Applications, John Wiley \& Sons: New York, pp. 1-34, 2009.

[12] Lelieveld, C.M.J.L., Smart Materials for the Realization of an Adaptive Building Component, Delft University of Technology: Delft, 2013.

[13] Speck, T., Knippers, J. \& Speck, O., Self-X materials and structures in nature and technology: bio-inspiration as a driving force for technical innovation. Architectural Design, 85(5), pp. 34-39, 2015.

http://dx.doi.org/10.1002/ad.1951

[14] Schleicher, S., Lienhard, J., Poppinga, S., Speck, T. \& Knippers, J., A methodology for transferring principles of plant movements to elastic systems in architecture. ComputerAided Design, 60, pp. 105-117, 2015.

http://dx.doi.org/10.1016/j.cad.2014.01.005

[15] Lienhard, J., Schleicher, S., Poppinga, S., Masselter, T., Milwich, M., Speck, T. \& Knippers, J., Flectofin: a hingeless flapping mechanism inspired by nature. Bioinspiration \& Biomimetics, 6(4), pp. 45-52, 2011. http://dx.doi.org/10.1088/1748-3182/6/4/045001

[16] Burgert, I. \& Fratzl, P., Actuation systems in plants as prototypes for bioinspired devices. Philosophical Transactions of the Royal Society of London A: Mathematical, Physical and Engineering Sciences, 367(1893), pp. 1541-1557, 2009.

[17] Liu, Y., Du, H., Liu, L. \& Leng, J., Shape memory polymers and their composites in aerospace applications: a review. Smart Materials and Structures, 23(2), pp. 1-23, 2014. http://dx.doi.org/10.1088/0964-1726/23/2/023001

[18] Lelieveld, C., Jansen, K. \& Teuffel, P., Mechanical characterization of a shape morphing smart composite with embedded shape memory alloys in a shape memory polymer 
matrix. Journal of Intelligent Material Systems and Structures, 1045389X15620035, 2015.

[19] Pickering, K., (eds), Matrices for natural-fibre reinforced composites (Chapter 2). In Properties and Performance of Natural-Fibre Composites, Elsevier: Amsterdam, pp. 67-126, 2008.

[20] Deshmukh, S.S. \& McKinley, G.H., Adaptive energy-absorbing materials using fieldresponsive fluid-impregnated cellular solids. Smart Materials and Structures, 16(1), pp. 106-113, 2006. http://dx.doi.org/10.1088/0964-1726/16/1/013

[21] Zhang, X.Z., Li, W.H. \& Gong, X.L., The rheology of shear thickening fluid (STF) and the dynamic performance of an STF-filled damper. Smart Materials and Structures, 17(3), pp. 27-35, 2008. http://dx.doi.org/10.1088/0964-1726/17/3/035027

[22] Woerner, M., Weickgenannt, M., Neuhaeuser, S., Goehrle, C., Sobek, W. \& Sawodny, O., Kinematic modeling of a hydraulically actuated 3-SPR-parallel manipulator for an adaptive shell structure. In Advanced Intelligent Mechatronics (AIM), 2013 IEEE/ ASME International Conference, IEEE, pp. 1330-1336, 2013.

[23] Ledezma-Ramirez, D., Ferguson, N. \& Brennan, M., Energy Dissipation using Variable Stiffness in a Single-Degree-of-Freedom Model, Eurodyn: Southampton, 2008. http://dx.doi.org/10.1016/j.jsv.2012.06.010

[24] Ledezma-Ramirez, D.F., Ferguson, N.S. \& Brennan, M.J., An experimental switchable stiffness device for shock isolation. Journal of Sound and Vibration, 331(23), pp. 4987-5001, 2012.

[25] Wagg, D., Bond, I., Weaver, P. \& Friswell, M. (eds), Adaptive structures -some biological paradigms (Chapter 10). In Adaptive Structures: Engineering Applications, John Wiley \& Sons: New York, pp. 261-283, 2008.

[26] Dye, S.F., The knee as a biologic transmission with an envelope of function: a theory. Clinical Orthopaedics and Related Research, 325, pp. 10-18, 1996. http://dx.doi.org/10.1097/00003086-199604000-00003 